\title{
Role of shrimp chitin in the ecology of toxigenic Vibrio cholerae and cholera transmission
}

\section{Shamsun Nahar ${ }^{1,2+}$, Marzia Sultana ${ }^{1 \dagger}$, M. Niamul Naser ${ }^{2}$, Gopinath B. Nair ${ }^{1,3}$, Haruo Watanabe ${ }^{4}$, Makoto Ohnishi ${ }^{4}$, Shouji Yamamoto ${ }^{4}$, Hubert Endtz ${ }^{1}$, Alejandro Cravioto ${ }^{1}$, R. Bradley Sack ${ }^{5}$, Nur A. Hasan ${ }^{6}$, Abdus Sadique ${ }^{1}$, Anwar Huq $^{6}$, Rita R. Colwell ${ }^{5,6,7 *}$ and Munirul Alam ${ }^{1}$}

\author{
${ }^{1}$ Laboratory Sciences Division, Enteric and food Microbiology, International Center for Diarrheal Disease Research, Dhaka, Bangladesh \\ 2 Department of Zoology, University of Dhaka, Dhaka, Bangladesh \\ ${ }^{3}$ National Institute of Cholera and Enteric Diseases, Kolkata, India \\ ${ }^{4}$ National Institute of Infectious Diseases, Tokyo, Japan \\ ${ }_{5}^{5}$ Johns Hopkins Bloomberg School of Public Health, Baltimore, MD, USA \\ ${ }^{6}$ Maryland Pathogen Research Institute, University of Maryland, College Park, MD, USA \\ ${ }^{7}$ Centre for Bioinformatics and Computational Biology, University of Maryland, College Park, MD, USA
}

\section{Edited by:}

Jonathan P. Zehr, University of

California Santa Cruz, USA

\section{Reviewed by:}

Jonathan P. Zehr, University of

California Santa Cruz, USA

Spencer V. Nyholm, University of

Connecticut, USA

Shawn R. Campagna, University of

Tennessee, Knoxville, USA

\section{*Correspondence:}

Rita R. Colwell, University of Maryland, College Park, 3103,

Biomolecular Sciences Building 296,

College Park, MD 20742, USA.

e-mail: rcolwell@umiacs.umd.edu

+ Shamsun Nahar and Marzia Sultana have contributed equally to this work.
Seasonal plankton blooms correlate with occurrence of cholera in Bangladesh, although the mechanism of how dormant Vibrio cholerae, enduring interepidemic period in biofilms and plankton, initiates seasonal cholera is not fully understood. In this study, laboratory microcosms prepared with estuarine Mathbaria water (MW) samples supported active growth of toxigenic $V$. cholerae $\mathrm{O} 1$ up to 7 weeks as opposed to 6 months when microcosms were supplemented with dehydrated shrimp chitin chips (CC) as the single source of nutrient. Bacterial counting and detection of wbe and ctxA genes were done employing culture, direct fluorescent antibody (DFA) assay, and multiplex-polymerase chain reaction methods. In MW microcosm, the aqueous phase became clear as the non-culturable cells settled, whereas the aqueous phase of the MW-CC microcosm became turbid from bacterial growth stimulated by chitin. Bacterial chitin degradation and biofilm formation proceeded from an initial steady state to a gradually declining bacterial culturable count. $V$. cholerae within the microenvironments of chitin and chitin-associated biofilms remained metabolically active even in a high acidic environment without losing either viability or virulence. It is concluded that the abundance of chitin that occurs during blooms plays an important role in the aquatic life cycle of $V$. cholerae and, ultimately, in the seasonal transmission of cholera.

Keywords: shrimp, chitin, biofilm, ecology, cholera, transmission

\section{INTRODUCTION}

Vibrio cholerae $\mathrm{O} 1$ is the causative agent of epidemic cholera, a severe dehydrating diarrheal disease that kills thousands each year and remains a serious health threat globally, notably in those countries where clean drinking water is less accessible to local populations. Cholera is an endemic disease in Bangladesh, occurring twice annually in two defined seasonal peaks, once in the spring and again in the autumn (Glass et al., 1982; Alam et al., 2006b). $V$. cholerae has been established as an autochthonous resident in the surface water of estuarine regions (Colwell and Spira, 1992; Lipp et al., 2002), where the bacterium survives in association with plankton (Huq et al., 1983), as well as in clusters of biofilms (Alam et al., 2006a,b). Plankton have been documented to play an important role in the seasonal cycle of $V$. cholerae by serving as a reservoir (Brayton and Colwell, 1987; Huq et al., 1990) and enhancing disease transmission (Colwell, 1996; Huq et al., 2005). Copepods, in general, Acanthamoeba castellanii (Huq et al., 1984; Abd et al., 2007), Acartia tonsa, and Eurytemora affinis (Rawlings et al., 2007), all contain chitin and are colonized by V. cholerae. Copepods, in particular, occur in the natural aquatic environment in seasonal blooms (Colwell and Huq, 1994). Attachment of $V$. cholerae to the hindgut, not to the midgut or foregut, of blue crab Callienectes sapidus strongly suggests a need of chitin in the attachment of the this pathogen (Huq et al., 1986), that might have a role in the transmission of cholera. Chironomid egg masses also have been shown to harbor high concentrations of non-toxigenic $V$. cholerae and have been proposed as a reservoir for the bacterium but they do not account for spring and autumn peaks in cholera incidence (Broza and Halpern, 2001).

Chitin is a biopolymer of $\beta$-1,4-linked $N$-acetylglucosamine (GlcNAc) and is abundant in both fresh and estuarine water systems where crustaceans are predominant and serve as the primary source of chitin (Gooday, 1990). Chitinous substrates influence the population dynamics of $V$. cholerae in a number of ways, including food availability, adaptation to environmental nutrient gradients, tolerance to stress, and protection from predators (Pruzzo et al., 2008). In the aquatic environment, chitin is heavily colonized by chitinolytic bacteria that are responsible for mineralization of this insoluble polysaccharide (Gooday et at., 1991). Binding to chitin in the environment may be either a casual phenomenon or 
promoted by chitin and/or chitin oligomers (Pruzzo et al., 2008). In this regard, chemotaxis of $V$. cholerae toward chitin oligosaccharides has been reported by Li and Roseman (2004) and the chitinase enzymes produced by $V$. cholerae have been proposed to assist in the degradation and utilization of the crustacean chitin colonized by these bacteria (Xibing et al., 2007). V. cholerae associated with crustaceans have been found to occur predominantly in a non-culturable state (Roszak and Colwell, 1987). Although non-culturability has long been proposed as a survival strategy for cholera bacteria in the aquatic environment between epidemics, the reservoir and mechanism by which these non-culturable cells regain culturability to initiate seasonal cholera are not fully understood. Despite the rate of isolation of $V$. cholerae O1 from fresh water being very low (Huq et al., 2005), recent epidemiological and ecological surveys carried out in Bangladesh provide firm evidence for an estuarine niche for $V$. cholerae because it has been shown to be present in biofilms in high abundance throughout the year (Colwell, 1996; Alam et al., 2006a). The question remains, nevertheless, what factor or factors influence activation of $V$. cholerae to the culturable state. It has been reported previously that salinity changes may trigger epidemics of cholera (Kaper et al., 1979). Correlation of sea surface temperature and plankton blooms in the Bay of Bengal with occurrence of cholera in Bangladesh has been established (Colwell, 1996) and a coastal connection of cholera has also been well documented for Bangladesh (Colwell, 1996; Huq et al., 2005), with cholera first striking coastal villages before cases occur inland (Siddique et al., 1991; Ramamurthy et al., 1993). Although the precise mechanism of how plankton populations in a bloom stimulate active growth of dormant, i.e., non-culturable, $V$. cholerae is not known, zooplankton serving as reservoir of $V$. cholerae constitute an important component of the food chain, in which larger crustaceans, such as shrimp, occupy the immediate upper trophic level. In the study reported here, the shrimp chitin that is present in abundance in the natural estuarine ecosystem of Bangladesh was used as nutrient in laboratory microcosms prepared with estuarine water to determine how shrimp chitin influences both the natural life cycle of $V$. cholerae and seasonal occurrence of cholera in the Sundarban region of Bangladesh.

\section{MATERIALS AND METHODS PREPARATION OF LABORATORY MICROCOSMS \\ Estuarine microcosms}

Microcosms were prepared with water collected from a pond in Mathbaria that serves as a drinking water source for villagers and had been tested positive for $V$. cholerae $\mathrm{O} 1$ by culture, DFA, and PCR (Alam et al., 2006a,b). Water for the microcosms (1 1 in each 2.51 conical flask) was filtered using $0.22 \mu \mathrm{m}$ membrane filtration to eliminate particulate matter (both biotic and abiotic) and autoclaved. V. cholerae O1 biotype El Tor N-16961 cells in exponential phase were harvested from Luria-Bertani (LB) broth incubated at $37^{\circ} \mathrm{C}$ for $18 \mathrm{~h}$, washed with phosphate buffered saline (PBS) at $\mathrm{pH} 7.0$, and inoculated to a final concentration of $10^{7} \mathrm{cfu} / \mathrm{ml}$ into microcosm flasks designated Mathbaria water (MW). The mouth of each of the flasks was sealed aseptically and incubated at room temperature $\left(25-33^{\circ} \mathrm{C}\right)$. Samples from the microcosms were collected aseptically at selected time intervals and examined by plating on thiosulfate citrate bile-salts sucrose (TCBS) and
LB agar media; serogroup was confirmed using polyvalent and monoclonal antiserum specific for $V$. cholerae O1 (Nandi et al., 2000). Aliquots of the samples were examined by direct fluorescent monoclonal antibody (DFA) staining (Brayton and Colwell, 1987; Hasan et. al., 1994) and multiplex-polymerase chain reaction (M-PCR) to detect toxigenic $V$. cholerae O1, following methods described elsewhere (Hoshino et al., 1998).

\section{MW microcosms supplemented with shrimp chitin chips}

Chitin was extracted from the carapaces of a large crustacean, the "golda" shrimp (Macrobrachium rosenbergii), collected from an estuary geographically adjacent to the coastal village of Mathbaria, Bangladesh following procedures described elsewhere (Sen, 2005). The chitin shells were washed, autoclaved, and dried at $60^{\circ} \mathrm{C}$ overnight and cut aseptically into small pieces. A microcosm was constructed using 11 filtered $(0.22 \mu \mathrm{m}$ membrane $)$ and autoclaved MW in 2.51 sterile conical flask, as described above. V. cholerae O1 biotype El Tor $\mathrm{N}-16961$ cells in exponential phase, collected after growth in LB broth at $37^{\circ} \mathrm{C}$ and washed with PBS (pH 7.0), were inoculated to a final concentration of $10^{7} \mathrm{cfu} / \mathrm{ml}$ into MW microcosms supplemented with shrimp chitin chips (CC $0.3 \%$; w/v) as sole source of nutrient. The microcosm amended with CC, designated MW-CC, was sealed aseptically and incubated at room temperature, as above. Samples were collected from the microcosms at selected time intervals and plated on TCBS and LB agar. Simple staining, DFA staining, and M-PCR were also performed to detect and enumerate $V$. cholerae $\mathrm{O} 1$. When culturable cell counts in the aqueous phase of the microcosm had declined to $<10$ on all culture media, the chitin residue at the bottom of the flask was treated with concentrated $\mathrm{HCl}(\mathrm{pH}$ 1.6-1.8) for $30 \mathrm{~min}$ to kill loosely attached bacteria, alkalinized with $\mathrm{NaOH}(\mathrm{pH} 7.0-9.0)$ for $30 \mathrm{~min}$, and the residue collected as a pellet by centrifugation. The pellet was washed with PBS several times and homogenized in PBS using a sterilized glass homogenizer (Elberbach Corp., Ann Arbor, MI, USA) to dislodge firmly attached bacteria. This homogenate was enriched in alkaline peptone water (APW) at $37^{\circ} \mathrm{C}$ for $24 \mathrm{~h}$, as described previously (Huq et al., 1990), plated on TCBS and LB agar, and analyzed by DFA and M-PCR to detect and enumerate V. cholerae O1 (Brayton and Colwell, 1987; Hasan et al., 1994; Hoshino et al., 1998; Nandi et al., 2000; Alam et al., 2006b).

\section{Simple staining}

Chitin chips from the microcosms were aseptically collected and placed on clean glass slides, air-dried, stained with $0.4 \%$ crystal violet (Sigma, St. Louis, MO, USA), washed, and visualized using a light microscope (Axioskop 40; Carl Zeiss AG, Gottingen, Germany). Images were recorded with a digital camera attachment (AxioCam MRc; Carl Zeiss AG, Gottingen, Germany).

\section{DFA}

Samples from MW and MW-CC microcosms were collected aseptically using wide-mouthed tips or sterile forceps and placed on a glass slide and stained with cholera DFA reagent (New Horizon Diagnostics, Columbia, MD, USA) following the methods, as described earlier (Brayton and Colwell, 1987; Hasan et al., 1994). At the initial stage, the intact CC from MW-CC microcosms were collected with sterile forceps. But, later on, the decaying CC were 
collected with wide-mouthed tips without disturbing the attached $V$. cholerae cells and the clusters of biofilm. Finally, the stained preparations were observed using an epifluorescence microscope (Axioskop 40; Carl Zeiss AG, Gottingen, Germany). Images were recorded with a digital camera attachment (AxioCam MRc; Carl Zeiss AG, Gottingen, Germany).

\section{M-PCR}

Vibrio cholerae $\mathrm{O} 1$ serotype specific $w b e$ genes encoding $\mathrm{O}$-antigen biosynthesis pathway and $\operatorname{ct} x A$ gene encoding subunit A of cholera toxin (CT) were amplified using M-PCR, details of which are provided elsewhere (Hoshino et al., 1998).

\section{RESULTS}

The MW and MW-CC microcosms inoculated with $V$. cholerae O1 yielded initial counts of $10^{7} \mathrm{cfu} / \mathrm{ml}$ on $\mathrm{LB}$ agar and counts of $10^{6} \mathrm{cfu} / \mathrm{ml}$ on TCBS agar (Table 1). The initial DFA counts (day 1) for MW and MW-CC microcosms were $3.8 \times 10^{8}$ and $3.5 \times 10^{8}$ cells $/ \mathrm{ml}$, respectively. M-PCR employing template DNA prepared from the two microcosms at day 1 amplified primers for $V$. cholerae $\mathrm{O} 1$ specific $w b e$ and $c t x \mathrm{~A}$ (Table 1). Bacterial plate counts for both microcosms, MW and MW-CC, declined to $10^{4}$ and $10^{3} \mathrm{cfu} / \mathrm{ml}$ on LB agar and TCBS agar, respectively, at day 7 and remained essentially stable until day 28 . Subsequently, a gradual reduction in plate count occurred in both microcosms, although cell counts were higher by one log in the MW-CC microcosm, compared to the MW microcosm (Table 1). In MW microcosm, plate counts declined to $<10$ on TCBS agar after 35 days and on LB agar after 49 days (Table 1). In contrast, the MW-CC microcosm, in which culturable cells were detected for a longer period of time, cell counts declined to $<10$ on TCBS agar after 76 days, whereas $V$. cholerae $\mathrm{O} 1$ produced colonies on LB agar until day 174 (Table 1) but not longer, as the cell count declined to $<10$ at day 189 .

In the MW microcosm, the wbe and $c t x A$ genes were amplified up to day 49 (Table 1), whereas DNA templates prepared from $V$. cholerae $\mathrm{O} 1$ cells inoculated and maintained in the MW-CC microcosm supported amplification of wbe and $\operatorname{ct} x A$ genes by $\mathrm{M}$ PCR up to 174 days, confirming presence of toxigenic $V$. cholerae O1 (Table 1).

The physical appearance of the MW-CC microcosm, in which $V$. cholerae $\mathrm{O} 1$ was maintained in autoclaved estuarine water supplemented with shrimp chitin as sole nutrient, was essentially clear and the CC were visible as intact pieces at day 1 (Figure 1A). Unlike the MW microcosm in which the aqueous phase was clear with the non-culturable cells settled to the bottom of the flask, the aqueous phase of the MW-CC microcosm became turbid with bacterial growth supported by chitin (Figure 1B). The process of chitin degradation continued up to 6 months, after which degraded chitin and bacteria comprised dense sediment at the bottom of the flask.

The shrimp CC in the MW-CC microcosm had the morphology of complex hexagonal structural units, i.e., "building blocks" of chitin, when viewed under the compound (light) microscope (Figure 2A). Crystal violet staining of the shrimp CC collected from the MW-CC microcosm at day 1 showed no sign of bacterial colonization (Figure 2A). However, at day 7, the shrimp CC clearly had been colonized by $V$. cholerae on the smooth surface of the CC (Figure 2B). With passage of time, the chitin surface was further colonized by $V$. cholerae, with a larger number of cells appearing in clusters of biofilm, coupled with apparent signs of chitin degradation (Figure 2C). Finally, the hexagonal structures of chitin disappeared and a smaller, degraded residue was detected that was heavily colonized by V. cholerae O1 (Figure 2D). Although degradation of chitin continued, $V$. cholerae O1 cells were seen mostly coccoid and embedded within biofilm clusters.

Vibrio cholerae DFA counts did not change in the MW microcosm until day 14 and cells in the MW microcosm could not be counted at day 21 because of transformation of the cells into large biofilm harboring mostly coccoid cells. Although initial DFA counts of $V$. cholerae $\mathrm{O} 1$ in the MW-CC microcosm were much the same as that of the MW microcosm, counting by DFA was not continued (Table 1) because of the clustering of cells and formation of micro-colonies that eventually turned into large biofilm clusters on the chitin (Figure 3A). At day 28, chitin degradation and biofilm formation had progressed (Figure 3B) simultaneously and the various sizes of degraded residues of the chitin were heavily colonized by $V$. cholerae $\mathrm{O} 1$ cells, mostly of coccoid morphology up to day 70 (Figures 2D and 3C).

In the MW-CC microcosm, $V$. cholerae $\mathrm{O} 1$ showed active growth up to day 174 , after which the cells became completely nonculturable $(<10 \mathrm{cfu})$ by day 189 . Although microscopic observation of the MW-CC microcosm revealed large clusters of a biofilm that contained coccoid cells at day 189 , a few rods were also detected. To examine whether the chitin biofilm serves as shelter for toxigenic $V$. cholerae $\mathrm{O} 1$, contents of the MW-CC microcosm were treated with concentrated $\mathrm{HCl}(\mathrm{pH}$ 1.7) for $30 \mathrm{~min}$, neutralized, and examined (see Materials and Methods), revealing the HCl-treated homogenate of the chitin biofilm preparation (Figure 3D) indeed contained $10^{4} \mathrm{cfu} / \mathrm{ml}$ of culturable $V$. cholerae O1 after enrichment in APW for $24 \mathrm{~h}$. This observation suggests that culturable $V$. cholerae $\mathrm{O} 1$ cells persist within chitin-induced biofilms and withstand adverse environmental conditions, in this case high acidity. DNA templates prepared from these $V$. cholerae O1 cells at day 189 amplified primers for wbe and ctxA by M-PCR (Table 1), providing evidence that toxigenic $V$. cholerae prevailed.

\section{DISCUSSION}

During its aquatic life cycle in nature, $V$. cholerae has been shown to persist between epidemic periods, predominately in the dormant (non-culturable) stage, in association with plankton (Brayton and Colwell, 1987; Huq et al., 1990). Although correlation of seasonal plankton blooms in the Bay of Bengal and occurrence of cholera has been shown for Bangladesh (Colwell, 1996), the precise mechanism of how plankton blooms contribute to the life cycle of $V$. cholerae in the aquatic environment is not fully understood. In the present study, shrimp chitin, that occurs in abundance during seasonal plankton blooms in the estuarine ecosystem of Bangladesh, was found to play an important role for toxigenic $V$. cholerae $\mathrm{O} 1$ by serving both as food and shelter, thereby, allowing biofilm formation and the cells to remain in an active growth stage for an extended period of time.

As has been demonstrated for $V$. parahemolyticus (Kaneko and Colwell, 1973), and V. cholerae O1 and non-O1 (Colwell et al., 1977), pandemic strains of $V$. cholerae adsorb and multiply on 
Table 1 | Comparison of $V$. cholerae 01 counts in Mathbaria pond water (MW) microcosms with and without chitin ${ }^{\mathrm{a}, \mathrm{b}}$.

\begin{tabular}{|c|c|c|c|c|c|c|c|}
\hline Day & Type of microcosm & \multicolumn{2}{|c|}{ Plate count (cfu/ml) } & Agglutinate $^{C}$ & $\begin{array}{l}\text { DFA } \\
\text { Cells/ml }\end{array}$ & \multicolumn{2}{|c|}{ Multiplex-PCR } \\
\hline & V. cholerae $\mathrm{O} 1$ in microcosm MW & $2.0 \times 10^{6}$ & $3.8 \times 10^{7}$ & + & $3.8 \times 10^{8}$ & + & + \\
\hline \multirow[t]{2}{*}{7} & $V$. cholerae $\mathrm{O} 1$ in microcosm MW-CC & $2.1 \times 10^{3}$ & $1.1 \times 10^{4}$ & + & $+^{d}$ & + & + \\
\hline & V. cholerae $\mathrm{O} 1$ in microcosm MW & $2.8 \times 10^{3}$ & $3.8 \times 10^{4}$ & + & $1.8 \times 10^{8}$ & + & + \\
\hline 14 & V. cholerae $\mathrm{O} 1$ in microcosm MW & $1.9 \times 10^{3}$ & $1.7 \times 10^{4}$ & + & $1.8 \times 10^{8}$ & + & + \\
\hline \multirow[t]{2}{*}{21} & V. cholerae $\mathrm{O} 1$ in microcosm MW-CC & $2.0 \times 10^{3}$ & $2.4 \times 10^{4}$ & + & $\mathrm{BF}^{\mathrm{d}}$ & + & + \\
\hline & $V$. cholerae $\mathrm{O} 1$ in microcosm MW & $1.6 \times 10^{3}$ & $2.8 \times 10^{4}$ & + & $\mathrm{BF}$ & + & + \\
\hline \multirow[t]{2}{*}{28} & V. cholerae $\mathrm{O} 1$ in microcosm MW-CC & $1.9 \times 10^{3}$ & $1.3 \times 10^{4}$ & + & $\mathrm{BF}^{\mathrm{d}}$ & + & + \\
\hline & $V$. cholerae $\mathrm{O} 1$ in microcosm MW & $1.1 \times 10^{3}$ & $4.8 \times 10^{4}$ & + & $\mathrm{BF}$ & + & + \\
\hline 35 & V. cholerae $\mathrm{O} 1$ in microcosm MW-CC & $1.6 \times 10^{2}$ & $1.1 \times 10^{3}$ & + & $\mathrm{BF}^{\mathrm{d}}$ & + & + \\
\hline \multirow[t]{2}{*}{49} & V. cholerae $\mathrm{O} 1$ in microcosm MW-CC & $7.7 \times 10^{1}$ & $2.4 \times 10^{2}$ & + & $\mathrm{BF}^{\mathrm{d}}$ & + & + \\
\hline & V. cholerae $\mathrm{O} 1$ in microcosm MW & $<10$ & $6.8 \times 10^{1}$ & + & $\mathrm{BF}$ & + & + \\
\hline \multirow[t]{2}{*}{56} & V. cholerae $\mathrm{O} 1$ in microcosm MW-CC & $6.7 \times 10^{1}$ & $1.4 \times 10^{2}$ & + & $\mathrm{BF}^{\mathrm{d}}$ & + & + \\
\hline & V. cholerae $\mathrm{O} 1$ in microcosm MW & $<10$ & $<10$ & NG & $\mathrm{BF}$ & ND & ND \\
\hline \multirow[t]{2}{*}{63} & V. cholerae $\mathrm{O} 1$ in microcosm MW-CC & $6.5 \times 10^{1}$ & $1.2 \times 10^{2}$ & + & $\mathrm{BF}^{\mathrm{d}}$ & + & + \\
\hline & $V$. cholerae $\mathrm{O} 1$ in microcosm MW & $<10$ & $<10$ & NG & $\mathrm{BF}$ & ND & ND \\
\hline \multirow[t]{2}{*}{70} & V. cholerae $\mathrm{O} 1$ in microcosm MW-CC & $6.4 \times 10^{1}$ & $1.0 \times 10^{2}$ & + & $\mathrm{BF}^{\mathrm{d}}$ & + & + \\
\hline & V. cholerae $\mathrm{O} 1$ in microcosm MW & $<10$ & $<10$ & NG & $\mathrm{BF}$ & ND & ND \\
\hline \multirow[t]{2}{*}{76} & V. cholerae $\mathrm{O} 1$ in microcosm MW-CC & $4.0 \times 10^{1}$ & $5.0 \times 10^{1}$ & + & $\mathrm{BF}^{\mathrm{d}}$ & + & + \\
\hline & V. cholerae $\mathrm{O} 1$ in microcosm MW & ND & ND & NG & ND & ND & ND \\
\hline 92 & V. cholerae $\mathrm{O} 1$ in microcosm MW-CC & $<10$ & $1.1 \times 10^{1}$ & + & ND & + & + \\
\hline \multirow[t]{2}{*}{146} & V. cholerae $\mathrm{O} 1$ in microcosm MW-CC & ND & $2.1 \times 10^{1}$ & + & ND & + & + \\
\hline & V. cholerae $\mathrm{O} 1$ in microcosm MW & ND & ND & NG & ND & ND & ND \\
\hline \multirow[t]{2}{*}{160} & V. cholerae $\mathrm{O} 1$ in microcosm MW-CC & ND & $2.1 \times 10^{1}$ & + & ND & + & + \\
\hline & V. cholerae $\mathrm{O} 1$ in microcosm MW & ND & ND & NG & ND & ND & ND \\
\hline 174 & V. cholerae $\mathrm{O} 1$ in microcosm MW-CC & ND & $1.0 \times 10^{1}$ & + & ND & + & + \\
\hline & V. cholerae $\mathrm{O} 1$ in microcosm MW & ND & ND & NG & ND & ND & ND \\
\hline 189 & V. cholerae $\mathrm{O} 1$ in microcosm MW-CC & ND & $<10$ & NG & $\mathrm{BF}^{\mathrm{d}}$ & $+^{e}$ & $+^{\mathrm{e}}$ \\
\hline & $V$. cholerae 01 in microcosm MW & ND & ND & NG & ND & ND & ND \\
\hline
\end{tabular}

${ }^{a}$ Microcosm was constructed using Mathbaria pond water, a known reservoir of V. cholerae (Alam et al., 2006a).

${ }^{b}$ Microcosm was constructed using Mathbaria pond water, a known reservoir of V. cholerae O1 (Alam et al., $\left.2006 a\right)$ and chitin chips.

'Vibrio cholerae 01 polyvalent and monoclonal antisera.

${ }^{d}$ Attachment of $\mathrm{V}$. cholerae 01 cells on chitin chip.

e Vibrio cholerae 01 cells from enrichment of $\mathrm{HCl}$-treated homogenized chitin residues.

Mathbaria water, Mathbaria pond water microcosm, inoculated with V. cholerae O1 grown on Luria-Bertani broth and maintained at room temperature; MW-CC, Mathbaria pond water microcosm with chitin chips, inoculated with V. cholerae $O 1$ grown on Luria-Bertani broth and maintained at room temperature; ND, not done; NG, no growth; BF, biofilms; CFU, colony forming unit; DFA, direct fluorescent antibody; TCBS, thiosulfate citrate bile sucrose agar; LB, Luria-Bertani agar.

chitinous fauna, including crabs, shrimp, and zooplankton (Nalin et al., 1979). Attachment to the chitinous layer of zooplankton enhances environmental fitness of Vibrio spp. by providing both an abundant source of carbon and nitrogen and protection from 

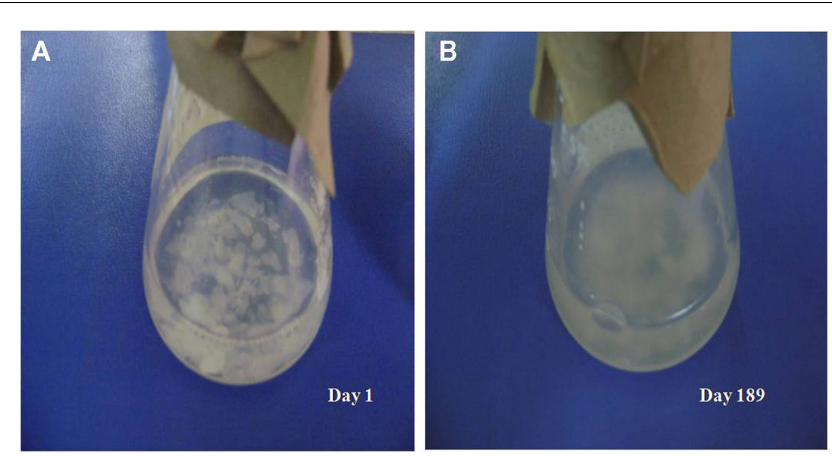

FIGURE 1 | External observation of the utilization of shrimp chitin in the MW-CC microcosm at room temperature (A) intact chitin chips at day 1 and (B) degraded chitin chips at day 189.
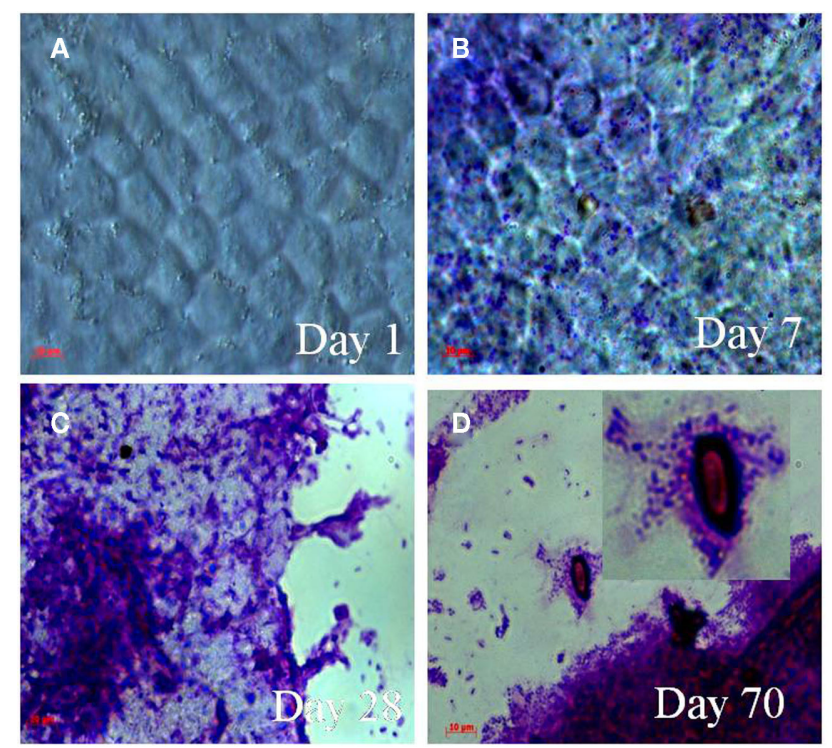

FIGURE 2 | Micrographs showing attachment and utilization of shrimp chitin by $\boldsymbol{V}$. cholerae $\mathbf{0 1}$ in $\mathbf{M W}-\mathbf{C C}$ microcosm. Samples were stained with $0.4 \%$ crystal violet. The stained samples were visualized using a light microscope (Carl Zeiss model Axioskop 40). Microscope images were captured digitally (AxioCam MRc) and processed using Adobe Photoshop (version 5). (A) Hexagonal structure of intact chitin chip at day 1 (B) attachment and colonization of the chitin chip by $V$. cholerae 01 cells at day 7; (C) aggregates of biofilm of $V$. cholerae $\mathrm{O} 1$ cells on decaying chitin chips at day 28; (D) thick biofilm and chitin residues colonized by $V$. cholerae 01 cells showing utilization of chitin (higher magnification in inset) at day 70 (Scale bars in red indicate $10 \mu \mathrm{m}$ ).

environmental challenges (Huq et al., 1984). Furthermore, particulate chitin and its soluble derivatives were shown to protect $V$. cholerae $\mathrm{O} 1$ against killing at low temperature (Amako et al., 1987). In this study, V. cholerae O1 colonizing shrimp chitin in the form of biofilm in microcosms prepared with water collected from Mathbaria, a cholera endemic estuarine area of Bangladesh, degraded chitin and remained in an active growth phase for up to 6 months, with strong evidence of utilization of the chitin as the
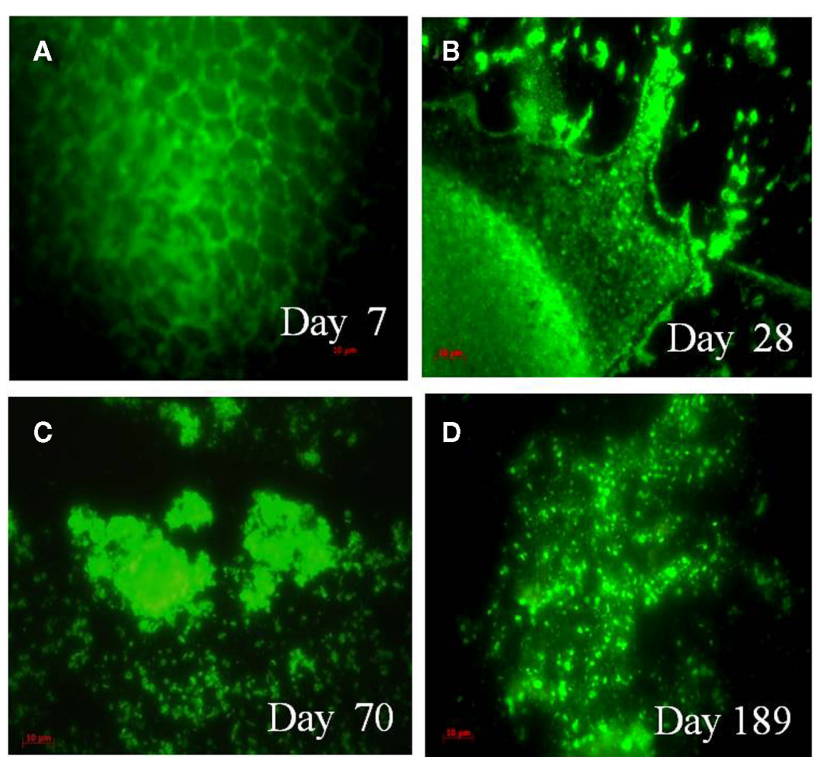

FIGURE 3 | Epifluorescent micrographs of attachment and utilization of shrimp chitin by $\boldsymbol{V}$. cholerae 01 in the MW-CC microcosm.

Fluorescent monoclonal antibody (DFA) specific for $V$. cholerae $\mathrm{O} 1$ obtained from New Horizon Diagnostics, were used and the stained cells were visualized using an epifluorescence microscope (Carl Zeiss model Axioskop 40). Microscopic images were captured digitally (AxioCam MRc) and processed using Adobe Photoshop (version 5). (A) Attachment and colonization of $V$. cholerae 01 on a chitin chip at day 7 ; (B) clusters of biofilm bound cells on a decaying chitin chip at day 28; (C) thick biofilm and small residues of chitin chips colonized by $V$. cholerae $\mathrm{O} 1$ (utilization of chitin) at day 70; (D) typical cells, dividing cells, together with mostly coccoid cells of $\mathrm{V}$. cholerae $\mathrm{O} 1$ in the homogenate of $\mathrm{HCl}$-treated chitin residue at day 189. (Scale bars in red indicate $10 \mu \mathrm{m}$ ).

source of nutrient (Xibing et al., 2007). In contrast, V. cholerae O1 was active for only ca. 49 days in the same water but without chitin. $V$. cholerae $\mathrm{O} 1$ in fresh water microcosms had previously been reported to be culturable for only up to 15 days (Huq et al., 1983; Islam et al., 1997), whereas in a recent study (Alam et al., 2007) $V$. cholerae $\mathrm{O} 1$ was found to be actively growing up to 40 days in estuarine water collected from Mathbaria. Thus, for survival and growth of $V$. cholerae, brackish, and estuarine water are concluded to be more supportive than fresh water (Alam et al., 2006a,b), presumably because of salinity and/or trace of soluble derivatives of chitin. More to the point, $V$. cholerae $\mathrm{O} 1$ in MW-CC was active for an extended period of time when chitin from shrimp, which occurs in abundance along with other crustaceans in the estuarine ecosystem of Mathbaria, was added to the microcosm water. Thus, the combination of estuarine water and chitinous fauna, including zooplankton, shrimp, and crabs, can explain, in part, why toxigenic $V$. cholerae is found for extended period of time in actively growing state in the estuarine ecosystem (Alam et al., 2006a,b, 2007), but less as in fresh water habitats where chitinous fauna are less abundant, but not absent (Huq et al., 1983, 2005; Islam et al., 1997).

Chitinase, an enzyme secreted by $V$. cholerae, is employed by the bacterium to colonize and degrade the insoluble polysaccharide 
component of chitin comprising the exoskeleton of fauna in the aquatic ecosystem (Gooday et al., 1991). Tamplin et al. (1990) had reported earlier that the chitinous surface of plankton served to concentrate $V$. cholerae $\mathrm{O} 1$, increasing the number of $V$. cholerae in a given unit of water. The strong affinity of $V$. cholerae for chitin was demonstrated by $V$. cholerae cells colonizing shrimp chitin extensively along the chitin surface, suggesting that chitin plays an important role in the aquatic life cycle of $V$. cholerae.

The $\operatorname{ctx} A$ and $\operatorname{ctx} B$ genes that encode CT subunits $A$ and $B$, respectively, are constituents of a lysogenic bacteriophage CTX $\phi$, whose genome consists of a core region encoding the CT responsible for the severity of the illness of cholera and other genes that code for virion morphogenesis (Waldor and Mekalanos, 1996; Alam et al., 2007). V. cholerae strains isolated from the natural aquatic environment are usually non-toxigenic (WHO, 2008) and toxigenic $V$. cholerae $\mathrm{O} 1$ maintained in estuarine microcosms lose CTX $\phi$ becoming non-toxigenic (Alam et al., 2007). A recent study demonstrated that chitin-induced competence of $V$. cholerae can lead to the emergence of genetic variants among toxigenic $V$. cholerae strains (Udden et al., 2008). Results presented in this study suggest that chitin can serve as food and reservoir for toxigenic $V$. cholerae in the estuarine environment.

Vibrio cholerae has been shown to be adapted to natural estuarine habitat, close to the mangrove forest of Bay of Bengal (Alam et al., 2006a,b, 2007), where crustaceans, namely shrimps, occur in abundance. Furthermore, toxigenic $V$. cholerae maintains itself during the interepidemic periods, between plankton blooms, without losing viability or virulence potential. The environment as a reservoir for toxigenic $V$. cholerae $\mathrm{O} 1$ and $\mathrm{O} 139$ in water and plankton has been well documented in earlier studies conducted in the USA (Rivera et al., 2003) and in Bangladesh (Alam et al., 2006a,b, 2007). The ability of $V$. cholerae to degrade chitin, previously documented by Colwell (1970) and observed in the present study, is characteristic of vibrios as well as many other marine bacteria (Keyhani and Roseman, 1999). Degradation of chitin involves four main steps: (i) sensing chitin; (ii) attachment to chitin; (iii) enzymatic degradation; and (iv) utilization of carbon and nitrogencontaining breakdown products (Somerville et al., 1989; Keyhani and Roseman, 1999). Chitin was shown to serve in the formation of surface-attached communities or biofilms by Watnick et al. (1999). In the present study, planktonic $V$. cholerae $\mathrm{O} 1$ colonized on the surface of the shrimp chitin, gradually increased the number by degrading chitin, and formed clusters of biofilms. The chitin particles and residues were heavily colonized by $V$. cholerae, the cells of which were embedded in a structured matrix. It may be concluded that chitin utilization supports $V$. cholerae to remain actively growing while biofilm formation is a simultaneous process that helps them remain together forming consortia.

In Bangladesh, cholera occurs seasonally, with two distinct seasonal peaks (epidemics), one before and the other after the annual monsoon (Glass et al., 1982). Toxigenic strains are isolated infrequently from surface waters by culture methods (Colwell and Huq, 1994) and very rarely during interepidemic periods (Huq et al., 1995). Because toxigenic V. cholerae is isolated only infrequently from surface water samples (Huq et al., 2005), this leaves its interepidemic aquatic reservoir an enigma. The estuarine ecosystem of Bangladesh is a natural habitat of toxigenic $V$. cholerae
(Siddique et al., 1991). Actively growing V. cholerae occurs predominantly during seasonal epidemics, and as aggregates of structured biofilms during interepidemic periods when they are found mostly as non-culturable cells (Alam et al., 2006a,b). The chitinous materials that occur in abundance in the estuarine water during seasonal plankton bloom, before and after the annual monsoon (Glass et al., 1982), likely play a role in the natural lifecycle of $V$. cholerae.

Attachment, survival, and proliferation of vibrios on surfaces of small crustaceans have been documented and the adhering bacteria have also been shown to be dormant, i.e., viable but non-culturable (Roszak and Colwell, 1987; Colwell, 1996). In the present study, DFA detection of $V$. cholerae O1 cells in chitinbound biofilms revealed the presence of mostly atypical and coccoid cells, together with a few typical curved rods. Culturable $V$. cholerae were isolated after prolonged treatment of the CC with $\mathrm{HCl}$, the significance being that $\mathrm{HCl}$ treatment killed planktonic or free swimming cells but not cells bound within the consortium of a biofilm. Ingested, biofilm bound cells in drinking water overcome the gastric acid barrier of the human stomach and reach the small intestine where conditions are alkaline (Colwell et al., 1996). Since chitin resists digestion by acid, vibrios can survive gastric transit if adherent to chitin ingested during a crab meal (Nalin et al., 1979).

In an estuarine ecosystem, crustaceans, namely shrimp, occupy the upper trophic level of the food chain and shrimp depend on zooplankton as food. Zooplankton is a well-established reservoir for V. cholerae (Huq et al., 1984; Colwell and Spira, 1992), depending, in turn, on phytoplankton as their primary food source. The brackish water habitat of the Sundarban, serves as an important niche for the $V$. cholerae that cause cholera epidemics in Bangladesh (Siddique et al., 1991; Alam et al., 2006a,b), but is also an ideal breeding ground for tiger shrimp, a popular food worldwide. This, taken with the epidemiological data showing that cholera emerges first in coastal villages (Siddique et al., 1991; Ramamurthy et al., 1993) may explain, in part, the cholera that subsequently occurs inland.

Previous studies showed $V$. cholerae, in the presence of chitin from plankton, grows actively up to 14 days, after which it became non-culturable (Huq et al., 1983). Because of the abundance and nutrient availability of shrimp chitin, toxigenic $V$. cholerae cells are maintained in an active growth phase for a relatively long time, i.e., months, accounting for its persistence in the environment between epidemics and in a dormant, i.e., viable but non-culturable state. A pre-epidemic enrichment of non-culturable $V$. cholerae in the human host has been proposed as an alternative method of amplification of an epidemic clone immediately before onset of an epidemic (Faruque et al., 2005). Given that actively growing cells of toxigenic $V$. cholerae can persist within chitin-induced biofilms in the natural estuarine ecosystem, as shown here, it is more likely that in situ enrichment of cholera bacteria occurs prior to human exposure, that is, during and following seasonal plankton blooms, when crustaceans containing $V$. cholerae serve as food for the shrimp population. Shrimp chitin and its chitin-related biofilm contain pathogenic $V$. cholerae, providing it with nutrient and shelter, thereby playing a significant role in the life cycle of $V$. cholerae and contributing to human disease transmission. 


\section{ACKNOWLEDGMENTS}

This research was partially supported by National Institute of Health (NIH) Research Grant 1RO1A13912901 under collaborative agreements between the Johns Hopkins Bloomberg School of Public Health, The University of Maryland and International Centre for Diarrheal Disease Research, Bangladesh (icddr,b), National Institute of Infectious Diseases (NIID), Tokyo, and NOAA Grant No. S0660009. Icddr,b acknowledges with gratitude the commitment of NIID, NOAA, and NIH to the

\section{REFERENCES}

Abd, H., Saeed, A., Weintraub, A., Nair, G. B., and Sandstrom, G. (2007). Vibrio cholerae O1 strains are facultative intracellular bacteria, able to survive and multiply symbiotically inside the aquatic freeliving amoeba Acanthamoeba castellanii. FEMS Microbiol. Ecol. 60, 33-39.

Alam, M., Sultana, M., Nair, G. B., Sack, R. B., Sack, D. A., Siddique, A. K., Ali, A., Huq, A., and Colwell, R. R. (2006a). Toxigenic Vibrio cholerae in the aquatic environment of Mathbaria, Bangladesh. Appl. Environ. Microbiol. 72, 2849-2855.

Alam, M., Hasan, N. A., Sadique, A., Bhuiyan, N. A., Ahmed, K. U., Nusrin, S., Nair, G. B., Siddique, A. K., Sack, R. B., Sack, D. A., Huq, A., and Colwell, R. R. (2006b). Seasonal cholera caused by Vibrio cholerae serogroups $\mathrm{O} 1$ and $\mathrm{O} 139$ in the coastal aquatic environment of Bangladesh. Appl. Environ. Microbiol. 72, 4096-4104.

Alam, M., Sultana, M., Nair, G. B., Siddique, A. K., Hasan, N. A., Sack, R. B., Sack, D. A., Ahmed, K. U., Sadique, A., Watanabe, H., Grim, C. J., Huq, A., and Colwell, R. R. (2007). Viable but nonculturable Vibrio cholerae $\mathrm{O} 1$ in biofilms in the aquatic environment and their role in cholera transmission. Proc. Natl. Acad. Sci. U.S.A. 104, 17801-17806.

Amako, K., Shimodori, S., Imoto, T., Miake, S., and Umeda, A. (1987). Effects of chitin and its soluble derivatives on survival of Vibrio cholerae $\mathrm{O} 1$ at low temperature. Appl. Environ. Microbiol. 53, 603-605.

Brayton, P. R., and Colwell, R. R. (1987). Fluorescent antibody staining method for enumeration of viable environmental Vibrio cholerae O1. J. Microbiol. Methods 6, 309-314.

Broza, M., and Halpern, M. (2001). Pathogen reservoirs: chironomid egg masses and Vibrio cholerae. Nature 412, 40.

Colwell, R. R. (1996). Global climate and infectious disease: the cholera paradigm. Science 274, 2025-2031.
Colwell, R. R. (1970). Polyphasic taxonomy and the genus Vibrio: numerical taxonomy of Vibrio cholerae, Vibrio parahaemolyticus, and related Vibrio species. J. Bacteriol. 104, 410-433.

Colwell, R. R., Brayton, P., Herrington, D., Tall, B., Huq, A., and Levine, M. M. (1996). Viable but nonculturable Vibrio cholerae $\mathrm{O} 1$ revert to a cultivable state in the human intestine. World J. Microbiol. Biotechnol. 12, 28-31.

Colwell, R. R., and Huq, A. (1994). Environmental reservoir of Vibrio cholerae: the causative agent of cholera. Ann. N. Y. Acad. Sci. 740, 44-54.

Colwell, R. R., Kaper, J., and Joseph, S. W. (1977). Vibrio cholerae, Vibrio parahemolyticus, and other Vibrios: occurrence and distribution in Chesapeake Bay. Science 198, 394-396.

Colwell, R. R., and Spira, W. M. (1992). "The ecology of Vibrio cholerae," in Cholera, eds D. Barua and W. B. I. Greenouh (New York: Plenum Press Inc.), 107-127.

Faruque, S. M., Islam, M. J., Ahmed, Q. S., Faruque, A. S. G., Sack, D. A., Nair, G. B., and Mekalanos, J. J. (2005). Self-limiting nature of seasonal cholera epidemics: role of host-mediated amplification of phages. Proc. Natl. Acad. Sci. U.S.A. 102, 6119-6124.

Glass, R. I., Huq, M. I., Stoll, B. J., Khan, M. U., Merson, M. H., Lee, J. V., and Black, R. E. (1982). Endemic cholera in rural Bangladesh, 1966-1980. Am. J. Epidemiol. 116, 959-970.

Gooday, G. W. (1990). The ecology of chitin degradation. Adv. Microb. Ecol. 11, 387-430.

Gooday, G. W., Prasser, J. L., Hillman, K., and Cross, M. G. (1991). Mineralization of chitin in an estuarine sediment: the importance of the chitosan pathway. Biochem. Syst. Ecol. 19, 395-400.

Hasan, J. A., Bernstein, K. D., Huq, A., Loomis, L., Tamplin, M. L., and Colwell, R. R. (1994). Cholera DFA: an improved direct fluorescent monoclonal antibody staining kit for rapid detection and enumeration of $V$.

Center's research efforts. Icddr,b also gratefully acknowledges the following donors which provide unrestricted support to the Centre's research efforts: Australian Agency for International Development (AusAID), Government of the People's Republic of Bangladesh, Canadian International Development Agency (CIDA), Embassy of the Kingdom of the Netherlands (EKN), Swedish International Development Cooperation Agency (SIDA), and the Department for International Development, UK (DFID).

cholerae O1. FEMS Microbiol. Lett. 120, 143-148.

Hoshino, K. S., Yamasaki, A. K., Mukhopadhyay, S., Chakraborty, A., Basu, S. K., Bhattacharya, S. K., Nair, G. B., Shimada, T., and Takeda, Y. (1998). Development and evaluation of a multiplex PCR assay for rapid detection of toxigenic Vibrio cholerae $\mathrm{O} 1$ and $\mathrm{O} 139$. FEMS Immunol. Med. Microbiol. 20, 201-207.

Huq, A., Colwell, R. R., Chowdhury, M. A., Xu, B., Moniruzzaman, S. M., Islam, M. S., Yunus, M., and Albert, M. J. (1995). Coexistence of Vibrio cholerae $\mathrm{O} 1$ and $\mathrm{O} 139$ Bengal in plankton in Bangladesh. Lancet 345, 1249.

Huq, A., Colwell, R. R., Rahaman, R., Ali, A., Chowdhury, M. A. R., Parveen, S., Sack, D. A., and Cohen, E. R. (1990). Detection of Vibrio cholerae $\mathrm{O} 1$ in the aquatic environment by fluorescent monoclonal antibody and culture methods. Appl. Environ. Microbiol. 56, 2370-2373.

Huq, A., Huq, S. A., Grimes, D. J., O’Brien, M., Chu, K. H., Capuzzo, J. M., and Colwell, R. R. (1986). Colonization of the gut of the blue crab (Callinectes sapidus) by Vibrio cholerae. Appl. Environ. Microbiol. 52, 586-588.

Huq, A., Sack, R. B., Nizam, A., Longini, I. M., Nair, G. B., Ali, A., Morris, J. G., Khan, M. N. H., Siddique, A. K., Yunus, M., Albert, M. J., Sack, D. A., and Colwell, R. R. (2005). Critical factors influencing the occurrence of Vibrio cholerae in the environment of Bangladesh. Appl. Environ. Microbiol. 71, 4645-4654.

Huq, A., Small, E., West, P., and Colwell, R. R. (1984). "The role of planktonic copepods in the survival and multiplication of Vibrio cholerae in the aquatic environment," in Vibrios in the Environment, ed. R. R. Colwell (New York: John Wiley and Sons), 521-534.

Huq, A., Small, E. B., West, P. A., Huq, M. I., Rahman, R., and Colwell, R. R. (1983). Ecological relationships between Vibrio cholerae and planktonic crustacean copepods. Appl. Environ. Microbiol. 45, 275-283.
Islam, M. S., Drasar, B. S., Albert, M. J., Sack, R. B., Huq, A., and Colwell, R. R. (1997). Toxigenic Vibrio cholerae in the environment: a minireview. Trop. Dis. Bull. 94, R1-R11.

Kaneko, T., and Colwell, R. R. (1973). Ecology of Vibrio parahemolyticus in Chesapeake Bay. J. Bacteriol. 3, 24-32.

Kaper, J., Lockman, H., Colwell, R. R., and Joseph, S. W. (1979). Ecology, serology, and enterotoxin production of Vibrio cholerae in Chesapeake Bay. Appl. Environ. Microbiol. 37, 91-103.

Keyhani, N. O., and Roseman, S. (1999). Physiological aspects of chitin catabolism in marine bacteria. Biochim. Biophys. Acta 1473, 108-122.

Li, X. B., and Roseman, S. (2004). The chitinolytic cascade in Vibrios is regulated by chitin oligosaccharides and a two components chitin catabolic sensor/kinase. Proc. Natl. Acad. Sci. U.S.A. 101, 627-631.

Lipp, E. K., Huq, A., and Colwell, R. R. (2002). Effects of global climate on infectious disease: the cholera model. Clin. Microbiol. Rev. 15, 757-770.

Nalin, D. R., Daya, V., Reid, A., Levine, M. M., and Cisneros, L. (1979). Adsorption and growth of Vibrio cholerae on chitin. Infect. Immun. 25 , 768-770.

Nandi, B., Nandi, R. K., Mukhopadhyay, S., Nair, G. B., Shimada, T., and Ghose, A. C. (2000). Rapid method for species-specific identification of $V$. cholerae using primers targeted to the gene of outer membrane protein OmpW. J. Clin. Microbiol. 38, 4145-4154.

Pruzzo, C., Vezzulli, L., and Colwell, R. R. (2008). Global impact of Vibrio cholerae interactions with chitin. Environ. Microbiol. 10, 1400-1410.

Ramamurthy, T., Garg, S., Sharma, R., Bhattacharya, S. K., Nair, G. B., Shimada, T., Takeda, Y., Karasawa, T., Kurazano, H., Pal, A., and Takeda, Y. (1993). Emergence of novel strains of Vibrio cholerae with epidemic potential in southern and eastern India. Lancet 341, 703-704. 
Rawlings, T. K., Ruiz, G. M., and Colwell, R. R. (2007). Association of Vibrio cholerae O1 El Tor and O139 Bengal with the Copepods Acartia tonsa and Eurytemora affinis. Appl. Environ. Microbiol. 73, 7926-7933.

Rivera, I. N. G., Lipp, E. K., Choopun, N., Gil, A., Huq, A., and Colwell, R. R. (2003). Method for DNA extraction and application of multiplex PCR to detect toxigenic Vibrio cholerae $\mathrm{O} 1$ and $\mathrm{O} 139$ in aquatic ecosystems. Appl. Environ. Microbiol. 5, 599-606.

Roszak, D. B., and Colwell, R. R. (1987). Survival strategies of bacteria in the natural environment. Microbiol. Rev. 51, 365-379.

Sen, D. P. (2005). Advances in Fish Processing Technology. Allied Publishers Private Limited, Mumbai.

Siddique, A. K., Baqui, A. H., Eusof, A., Haider, K., Hossain, M. A., Bashir, I., and Zaman, K. (1991). Survival of classic cholera in Bangladesh. Lancet 33, 1125-1127.
Somerville, C. C., Knight, I. T., Straube, W. L., and Colwell, R. R. (1989). Simple rapid method for direct isolation of nucleic acids from aquatic environments. Appl. Environ. Microbiol. 55, 548-554.

Tamplin, M. L., Gauzens, A. L., Huq, A., Sack, D. A., and Colwell, R. R. (1990). Attachment of Vibrio cholerae serogroup $\mathrm{O} 1$ to zooplankton and phytoplankton of Bangladesh waters. Appl. Environ. Microbiol. 56, 1977-1980.

Udden, S. M. N., Zahid, M. S. H., Biswas, K., Ahmad, Q. S., Cravioto, A., Nair, G. B., Mekalanos, J. J., and Faruque, S. M. (2008). Acquisition of classical CTX prophage from Vibrio cholerae O141 by El Tor strains aided by lytic phages and chitin-induced competence. Proc. Natl. Acad. Sci. U.S.A. 105, 11951-11956.

Waldor, M. K., and Mekalanos, J. J. (1996). Lysogenic conversion by a filamentous bacteriophage encoding cholera toxin. Science 272, 1910-1914.
Watnick, P. I., Fullner, K. J., and Kolter, R. (1999). A role for the mannosesensitive hemagglutinin in biofilm formation by Vibrio cholerae El Tor. J. Bacteriol. 181, 3606-3609.

World Health Organization. (2008). Cholera: global surveillance summary, 2008. Wkly. Epidemiol. Rec. 84, 309-324.

Xibing, L., Wang, L. X., and Roseman, S. (2007). The chitin catabolic cascade in the marine bacterium Vibrio cholerae: characterization of a unique chitin oligosaccharide deacetylase. Glycobiology 17 1377-1387.

Conflict of Interest Statement: The authors declare that the research was conducted in the absence of any commercial or financial relationships that could be construed as a potential conflict of interest.
Received: 10 October 2011; paperpending published: 01 November 2011; accepted: 05 December 2011; published online: 04 January 2012.

Citation: Nahar S, Sultana M, Naser MN, Nair GB, Watanabe H, Ohnishi $M$, Yamamoto $S$, Endtz H, Cravioto A, Sack RB, Hasan NA, Sadique A, Huq A, Colwell RR and Alam M (2012) Role of shrimp chitin in the ecology of toxigenic Vibrio cholerae and cholera transmission. Front. Microbio. 2:260. doi: 10.3389/fmicb.2011.00260

This article was submitted to Frontiers in Aquatic Microbiology, a specialty of Frontiers in Microbiology.

Copyright (C) 2012 Nahar, Sultana, Naser, Nair, Watanabe, Ohnishi, Yamamoto, Endtz, Cravioto, Sack, Hasan, Sadique, Huq, Colwell and Alam. This is an open-access article distributed under the terms of the Creative Commons Attribution Non Commercial License, which permits non-commercial use, distribution, and reproduction in other forums, provided the original authors and source are credited. 